\title{
Simulated annealing approach for solving economic load dispatch problems with valve point loading effects
}

\author{
Kamlesh Kumar Vishwakarma ${ }^{1}$, Hari Mohan Dubey ${ }^{2 *}$, Manjaree Pandit ${ }^{3}$ and B.K. Panigrahi ${ }^{4}$ \\ 1,2*3 Department of Electrical Engineering, Madhav Institute of Technology \& science Gwalior, INDIA \\ ${ }^{4}$ Department of Electrical Engineering, Indian Institute of Technology Delhi, INDIA \\ "Corresponding Author: harimohandubeymits@gmail.com, Tel +91-0751-2409215, +91-0751-2409380
}

\begin{abstract}
This paper presents Simulated Annealing (SA) algorithm for optimization inspired by the process of annealing in thermodynamics to solve economic load dispatch (ELD) problems. The proposed approach is found to provide optimal results while working with operating constraints in the ELD and valve point loadings effects. In order to prove the robustness of the algorithm it is investigated on four different standard test cases consisting of 3, 13, 40 generating unit system with valve point effect and a Crete Island system of 18 thermal generating units having convex fuel cost characteristics. The proposed method has been compared with other existing relevant approaches available in literatures. Experimental results support to justify superiority of the approach over other reported techniques in terms of fast convergence, robustness and most significantly its optimal search behavior.
\end{abstract}

Keywords: Thermodynamics, Simulated Annealing, Economic load dispatch, Valve point loadings effects.

DOI: http://dx.doi.org/10.4314/ijest.v4i4.6

\section{Introduction}

Economic operation is very important for a power system to get profits on the capital invested (Song et al., 1996). Operational economics involving power generation and delivery can be sub divided into two parts:1) minimization of power production cost, called economic load dispatch 2) minimization of transmission losses. Functionally Optimum Power Flow (OPF) combines the power flow with Economic Load Dispatch (ELD) problem (Sun et al. 1984; Yuryevich et al. 1999; AlRashidi et al.2007). The objective of OPF is to find the optimal settings of a given power system network that optimize a certain objective function (based on losses, reactive power, voltage or power flow violations etc.) while system security, and all operating constraints are satisfied. The most commonly used objective is the minimization of the overall fuel cost function along with minimization of active power loss, bus voltage variation, emission of power generating units, and power shedding. On the other hand, ELD is one of the most crucial issues of present energy management system. The objective of ELD in a power system is to discover the best possible combination of power output for all generating units which will minimize the total fuel cost as well as satisfying load and operational constraints. The ELD problem is extremely complex to work out because of its large dimension, a non-linear objective function, and various constraints. several analysis on the ELD have been carried out till now, suitable improvements in the unit outputs scheduling can contribute to significant cost savings (Choudhary et al. 1990; Happ et al. 1971) and also information in forming market clearing prices is provided by it.

Various classical optimization techniques were used to solve the ELD problem, for example: lambda iteration approach, gradient method, linear programming method and Newton's method (Wood et al.1996). Lambda iteration method, the most common one has been applied to solve ELD problems. But for its effective implementation, the formulations have to be 
continuous. Linear programming methods is fast and reliable but the main weakness is they are associated with the piecewise linear cost approximation (Park et al.1993).

In order to get the qualitative solution for problem related to ELD, Artificial Neural Network (ANN) techniques such as Hopfield Neural Network (HNN) (Park et al.1993) have been used. The objective function of the ELD problem is transformed into a Hopfield energy function and arithmetical iterations are utilized to minimize the energy function. To solve the ELD problems for power generating units associated with continuous or piecewise quadratic fuel cost functions and for units with prohibited zone constraints Hopfield model has been employed. In the conventional HNN, the input-output correlation for its neurons can be depicted by sigmoid function. Hopfield model takes more iteration to present the solution and large computational time due to use of the sigmoid function to solve the ED problems.

Recently, various other nature inspired optimization techniques have proved their potential in handling various problems. The prominent among them are genetic algorithm (GA) (Walter et al., 1993), evolutionary programming (EP) (Yang et al., 1996), particle swarm optimization (PSO) (Park et al., 2005), differential evolution (DE) (Coelho et al., 2006) , Artificial Bee Colony Algorithm (ABC) (Hemamalini et al., 2008), Biogeography-Based optimization(BBO) (Bhattacharya et al., 2010), Bacterial foraging-based optimization (BFBO) (Padmanabhan et al.,2011) ,Firefly Algorithm (FA) (Yang et al.2012) etc. Improved fast evolutionary programming algorithm has been successfully applied for solving the ELD problem (Choudhary et al. 1990; Lee et al. 1984). Other algorithms like Hybrid genetic/simulated-annealing approach (GA/SA)(Wong et al. 1994), Hybrid particle swarm optimization sequential quadratic programming (PSO-SQP) (Aruldoss et al., 2004), Chaotic particle swarm optimization (CPSO) (Jiejin et al., 2007), new particle swarm with local random search (NPSO-LRS) (Selvakumar et al., 2007), Improved particle swarm optimization (Ning et al. 2007), Self-Organizing Hierarchical particle swarm optimization (SOH-PSO) (Chaturvedi et al. 2008), Bacterial foraging optimization nelder mead hybrid algorithm (BFONM) (Panigrahi et al., 2008), improved coordination aggregated based PSO (ICA_PSO)(John et al., 2009), quantum-inspired PSO (QPSO)(Meng et al., 2010), and modified group search optimizer algorithm (MGSO) (Zare et al., 2012) have been applied to solve the ELD problem.

Simulated Annealing (SA) is a stochastic optimization approach inspired by the natural process of annealing related to thermodynamics proposed by (Kirkpatrick et al., 1983). SA approach has been previously applied to solve ELD problem (Wong et al.1993), dynamic economic dispatch problem (Panigrahi et al., 2007) for small large dimensional ELD problems with convex cost characteristics (Vishwakarma et al., 2012) .In this paper the potential of simulated annealing approach has been tested for large dimensional ELD problem with nonconvex cost characteristics. One of the test systems used is known be particularly difficult to optimize as it has multiple local minima (Sinha et al., 2003).

In order to validate robustness and effectiveness of SA algorithm, this paper considers four standard ELD problems, namely, 3 13 and 40 generating unit system with valve-point loading effects and an 18 generating unit systems with quadratic cost function with varying percentage of the maximum power as demand.

The paper is organized as follows: brief description and mathematical formulation of ELD problems presented in Section 2 . The concept behind the simulated annealing (SA) optimization is discussed in Section 3. Section 4 depicts realization process of the algorithm used for the test system. Section 5 related to discussion in contest of parameter settings for the used test cases to analyze performance of SA. Concluding remarks are presented in Section 6.

\section{Economic Load Dispatch Formulation}

The objective of ELD problem is to minimize the fuel cost of generating units for a specific period of operation so as to accomplish optimal generation dispatch among operating units while the system load demand, generator operational constraints, ramp rate limit and prohibited operating zones are satisfied. Two models for ELD are considered here, one with smooth cost function and other with non smooth cost function as below.

The objective function analogous to the generation cost can be approximated to be a quadratic function. Symbolically, it is represented as

$\operatorname{Minimize} \mathrm{F}_{\mathrm{t}}^{\cos \mathrm{t}}=\sum_{\mathrm{i}=1}^{\mathrm{N}_{\mathrm{G}}} f_{\mathrm{i}}\left(\mathrm{P}_{\mathrm{i}}\right)$

Where $f_{\mathrm{i}}\left(\mathrm{P}_{\mathrm{i}}\right)=\mathrm{a}_{\mathrm{i}} \mathrm{P}_{\mathrm{i}}^{2}+\mathrm{b}_{\mathrm{i}} \mathrm{P}_{\mathrm{i}}+\mathrm{c}_{\mathrm{i}}, \quad \mathrm{i}=1,2,3, \ldots, \mathrm{N}_{\mathrm{G}}$

is the expression for cost function of $i^{\text {th }}$ generating unit and $a_{i}, b_{i}$ and $c_{i}$ are its cost coefficients. $P_{i}$ is the real power output (MW) of $\mathrm{i}^{\text {th }}$ generator corresponding to time period $\mathrm{t} . \mathrm{N}_{\mathrm{G}}$ is the number of generating units.

The sequential valve opening process for multi-valve steam is responsible for ripple in heat rate curve. These effects are included in cost function using sinusoidal component as

$$
f_{i}\left(P_{i}\right)=a_{i} P_{i}^{2}+b_{i} P_{i}+c_{i}+\left|e_{i} \sin \left(f_{i}\left(P_{i}^{\min }-P_{i}\right)\right)\right|
$$


Where $e_{i}$ and $f_{i}$ are the cost coefficients corresponding to valve point loading effect.

The ELD problem consists of minimizing $\mathrm{F}_{\mathrm{t}}{ }^{\text {Cost }}$ subjected to following constraints.

2. A) Power Balance Constraints: The total generation must fulfill the total demand plus losses. If total system load is $P_{D}$ and losses are represented by $\mathrm{P}_{\mathrm{L}}$, then,

$\sum_{i=1}^{N_{G}} P_{i}=P_{D}+P_{L}$

Where transmission loss $\mathrm{P}_{\mathrm{L}}$ is expressed using B- coefficients (wood et al, 1996), given by

$$
P_{L}=\sum_{i=1}^{N_{G}} \sum_{j=1}^{N_{G}} P_{i} B_{i j} P_{j}+\sum_{i=1}^{N_{G}} B_{0 i} P_{i}+B_{00}
$$

2. B) Generator Capacity Constraints: For stable operation, real power generated by each generator restricted by their lower limit $P_{i}^{\min }$ and upper limit $P_{i}^{\max }$ as follows:

$$
\mathrm{P}_{\mathrm{i}}^{\min } \leq \mathrm{P}_{\mathrm{i}} \leq \mathrm{P}_{\mathrm{i}}^{\max }
$$

\section{Optimization using Simulated Annealing}

Simulated Annealing is basically a stochastic optimization technique inspired by the natural process of crystallization i.e. gradual cooling of metal. Annealing (in metallurgy \& material science) is a process involving heating and controlled cooling of a material to get perfect crystal with minimum defects. There is a significant correlation between the terminology of thermodynamic annealing process (the behavior of systems with many degrees of freedom in thermal equilibrium at a finite temperature) and combinatorial optimization (finding global minimum of a given function based on many parameters).A detailed analogy of annealing in solids provides frame work for optimization. Table 1 depicts the key terms which are related with thermodynamic annealing and its association with optimization process.

Table 1: Association among thermodynamic simulation and Combinatorial Optimization

\begin{tabular}{|l|l|}
\hline Thermodynamic annealing & \multicolumn{1}{c|}{ Simulated annealing } \\
\hline System state & Feasible Solutions \\
\hline Energy & Cost \\
\hline Change of state & Neighboring Solutions \\
\hline Temperature & Control Parameter \\
\hline Frozen state & Heuristic Solution \\
\hline
\end{tabular}

The main advantage of SA approach is that it does not need large computer memory. Whenever a large number of local minima are available, then the search for global minima for a multidimensional function becomes quite a complex task. The main purpose of the optimization is to achieve fast convergence as well as better exploration capability. The SA method has ability to escape from local minima by incorporating a probability function in accepting and rejecting new solutions.

3. A) Annealing Process in Thermodynamics: Molecules of a metal become unstuck from their initial positions and wander randomly at high temperature. By gradual cooling thermal mobility is lost and atoms start to get arranged in the form of a crystal. If the reduction of temperature is done at a very fast rate, a meta-stable state (i.e. crystalline state transforms to an amorphous structure) is obtained which corresponds to a local minima of energy level (Kolahan et al. 2010).

For a thermal equilibrium state of a system for temperature $T$, afterward the probability $P_{T}(s)$ with its pattern $s$ depends on energy level of corresponding pattern $E(s)$, and is depending on Boltzmann distribution

$P_{T}(s)=\frac{e^{-E(s) / k T}}{\sum_{W} e^{-E(w) / k T}}$ 
Where, $k$ is known as Boltzmann constant and the sum $\Sigma_{W}$ consists of all promising states of $W$.

Metropolis et al. (1953) were the first to suggest a method for calculating a distribution of a system of elementary particles (molecules) at the thermal balance state.

Let the system have a configuration $\mathrm{g}$, which corresponds to energy $E(g)$. If one of the molecules of the system is displaced from its initial position, then a new state $\sigma$ corresponding to energy $E(\sigma)$ occurs. If $E(\sigma) \leq E(g)$, then the new state is accepted. If $E(\sigma)>E(g)$, then the new state is accepted with probability :

$$
e^{-(E(\sigma)-E(g)) / K T}
$$

3. B) Critical parameters of SA algorithm: For the successful application of the SA algorithm, the annealing schedule is vital. There are four control parameters that are directly associated with its convergence (to an optimized solution) and its efficiency (Kolahan et al, 2010). They are,

I) Initial Temperature

II) Final Temperature

III) Rate of Temperature Decrement and

IV) Iteration at each Temperature

\section{I) Initial Temperature}

At beginning, Initial temperature must be set at a higher value, in order to get more probability of acceptance for non optimized solutions during the first stages of the algorithm. Too much higher selection of initial temperature makes an algorithm slow and computationally inefficient. On the other hand, very low initial temperature may not be capable of searching a minimum especially for multi model function. There is no particular way to find out proper initial temperature which is suitable for whole range of problems. According to Dowsland et al. (1995), if the temperature of the system is raised quickly up to the initial value, where a certain percentage of the worst solutions is acceptable. After this, a gradual decrement of temperature is proposed.

\section{II) Final Temperature}

While working with SA algorithm generally the final temperature fall is set to zero degree Celsius. SA algorithm can take much longer time to execute the operation, if the decrement in the temperature is exponential in nature. Finally, the stopping criterion is selected, which can be either a appropriate low temperature or the value where the system get freeze at that temperature.

\section{III) Temperature Decrement}

As initial and final temperatures have predefined values, it is essential to find the approach of transition from starting to its final temperature as the success of algorithm depends on it. According to Aarts et al,(1988) decrement of temperature at time " $t$ " is:

$$
T(t)=d / \log (t)
$$

Where $d$ is a positive constant.

The temperature decrement can also be implemented using $T(t+1)=a T(t)$

Where $a$, is a constant close to 1 . Its effective range is $0.8 \leq \mathrm{a} \leq 0.99$.

\section{IV) Iterations at each Temperature}

To enhance efficiency of the algorithm, selection of proper number of iterations is another important factor. Lundy et al. (1985) suggests the realization of only one iteration for each temperature and the fall in temperature should take place at a really slow rate which can be expressed as:

Generally, $\beta$ have very small value.

$$
T(t)=t /(1+\beta \cdot t)
$$

\section{SA Algorithm Implementation of ELD Problems}

Step1: For initialization, choose temperature $T$, parameter $\alpha$ and maximum number of iterations 'max tries', to generate an initial feasible solution by random process and store it as current solution Si. Then performs ELD in order to evaluate the total cost, $F_{\text {cost }}$, while satisfying power balance as well as generator constraints as in eq. (4) and eq. (6) respectively.

Step2: Set the iteration counter to $\mu=1$ 
Step3: Create an adjacent solution $S_{j}$ through the rand operator and compute the new total cost, $F_{\text {cost }}$.

Step4: If the new solution is found to be better, accept it; otherwise find the deviation of $\operatorname{cost} \Delta S_{j}=S_{j}-S_{i}$ and generate a random number $\Omega \in(0,1)$ out of a uniform distribution using the following logic:

If $e^{-\Delta S / t} \geq \Omega \in(0,1)$

Accept the new solution $S_{j}$ to replace $S_{i}$.

Step5: Reduce temperature by parameter $\alpha$, until the stopping criterion is not satisfied

$T(t)=\alpha . T$, and go back to Step 2.

\section{Results and Discussion}

The proposed SA-based approach has been developed and implemented using the MATLAB software. In order to investigate the robustness of the proposed method we experimented with four standard test cases. They are 3 unit system, 13 unit system, 18 unit systems with a varying percentage of the maximum power as demand and a large system consisting of 40 generating unit. The programs were developed using MATLAB 7.1 and the system configuration is Pentium IV processor with 2.4 GHz speed and 512 MB RAM.

\subsection{Selection of control Parameters}

As in other evolutionary optimization approach, SA algorithm also needs appropriate selection control parameter before implementation. Because optimum parameter selection finally responsible for smooth fitness convergence. The following process has been applied to determine optimal values of parameters such as initial temperature, final temperature, consecutive rejection and maximum number of iterations, which is used here as a stopping criteria. A standard test system with 3 generating units [Walter et al. (1993)] having valve point loading effects is used to locate the best control parameters. Load demand of the system is set at $850 \mathrm{MW}$. For conducting the test, the initial temperature is fixed at $300^{\circ} \mathrm{C}$, alpha is increased from 0.5 to 0.99 in suitable steps and max tries is varied from 1000 to 10000 as shown in Table 2 and further initial temperature is increased from $100^{\circ} \mathrm{C}$ to $400^{\circ} \mathrm{C}$ as given in Table 3 .

Table 2: Influence of parameters on SA performance Initial Temperature $=300^{\circ} \mathrm{C}$

\begin{tabular}{|c|c|c|c|c|c|c|}
\hline \multirow[t]{2}{*}{ Max. Tries } & \multicolumn{6}{|c|}{ alpha } \\
\hline & 0.5 & 0.6 & 0.7 & 0.8 & 0.9 & 0.99 \\
\hline 1000 & 8424.69608 & 8369.93635 & 8343.93784 & 8241.18305 & 8234.07179 & 8234.07180 \\
\hline 4000 & 8424.69608 & 8241.17563 & 8294.33710 & 8241.58756 & 8250.20597 & 8234.07173 \\
\hline 7000 & 8424.69608 & 8241.17678 & 8241.18786 & 8234.07181 & 8241.58753 & 8234.07174 \\
\hline 10000 & 8424.69608 & 8241.17981 & 8241.17469 & 8241.17537 & 8234.07175 & 8234.07162 \\
\hline
\end{tabular}

Table 3: Effect of initial temperature on 3 unit non convex system $(\mathrm{PD}=850 \mathrm{MW})$ with alpha $=0.99$, max. tries $=1000$

\begin{tabular}{|c|c|c|c|c|c|c|c|}
\hline $\begin{array}{c}\text { Initial } \\
\text { Temperature } \\
\left(\mathbf{~} \mathbf{0}^{\mathbf{C}}\right)\end{array}$ & Pg1 & Pg2 & Pg3 & $\begin{array}{c}\text { Minimum } \\
\text { Cost } \mathbf{( \$ / h r )}\end{array}$ & $\begin{array}{c}\text { Mean Cost } \\
\mathbf{( \$ / h r )}\end{array}$ & $\begin{array}{c}\text { Max. } \\
\text { Cost (\$/hr) }\end{array}$ & $\begin{array}{c}\text { Std. } \\
\text { Deviation }\end{array}$ \\
\hline 100 & 600.00 & 174.80 & 50.00 & 8369.93466 & 8446.23 & 8446.23 & 67.79 \\
\hline 200 & 498.93 & 251.18 & 99.89 & 8241.20354 & 8288.51 & 8288.51 & 81.60 \\
\hline $\mathbf{3 0 0}$ & $\mathbf{3 0 0 . 2 7}$ & $\mathbf{4 0 0 . 0 0}$ & $\mathbf{1 4 9 . 7 3}$ & $\mathbf{8 2 3 4 . 0 7 1 6 2}$ & $\mathbf{8 2 3 4 . 0 7}$ & $\mathbf{8 2 3 4 . 0 7}$ & $\mathbf{0 0 . 0 0}$ \\
\hline 400 & 300.27 & 400.00 & 149.73 & 8234.07176 & 8234.07 & 8234.07 & 00.00 \\
\hline
\end{tabular}

Over 20 repeated trials, the SA algorithm was successful in achieving a minimum cost \$8234.07162/hr and standard deviation 0.00000 with the tuning parameters value: initial temperature $=300^{\circ} \mathrm{C}$, alpha $=0.99$; and $\max$. tries $=10000$, which is used for analysis of other problems. 


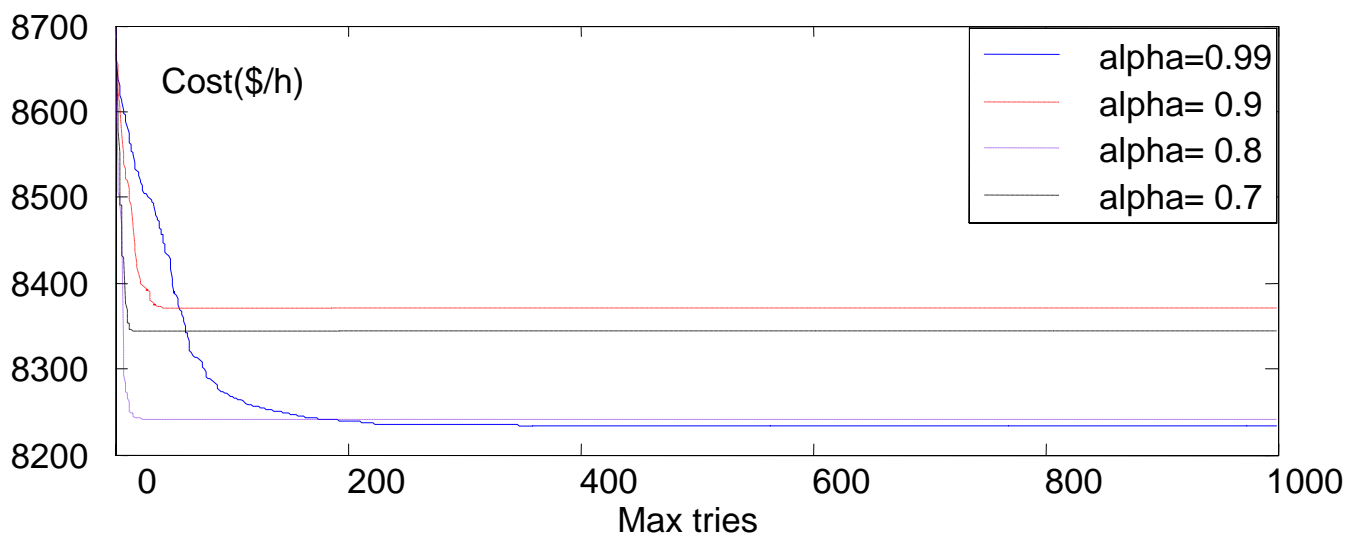

Figure 1: Convergence of 3 Generators system $\mathrm{PD}=850 \mathrm{MW}$

Test Case 1: Three Unit System

The test system consists of 3 generating units with valve point loading effect with total load demand of $850 \mathrm{MW}$. Because of the small dimension of the problem, the global best cost of this example is known and the main target is to show that the global best output can also be obtained by the SA approach.Result obtained using SA method is and compared with genetic algorithm (GA), evolutionary programming (EP), Hybrid particle swarm optimization sequential quadratic programming (PSO-SQP), Artificial Bee Colony Algorithm (ABC) and modified group search optimizer algorithm (MGSO) in Table 4. The minimum cost attained by the SA method is $8234.07 \$ / \mathrm{hr}$ which indicates that the SA approach is capable of producing the global best results.

Table 4: Comparison of Results for 3 unit system

\begin{tabular}{|l|l|l|l|l|l|l|}
\hline Algorithm & Pg1(MW) & Pg2(MW) & Pg3(MW) & PD (MW) & Min cost (\$/hr) & Ave cost (\$/hr) \\
\hline GA (Walter et al. 1993) & 299.100 & 399.000 & 150.800 & 850 & 8239.20 & ---- \\
\hline EP (Yang H.T et al. 1996) & 300.264 & 400.000 & 149.736 & 850 & 8234.07 & 8234.16 \\
\hline PSO-SQP (Aruldoss et al. 2004) & 300.267 & 400.000 & 149.733 & 850 & 8234.07 & 8234.07 \\
\hline ABC (Hemamalini et al . 2008) & 300.260 & 400.000 & 149.740 & 850 & 8234.07 & ---- \\
\hline MGSO (Zare et al. 2012 ) & 300.2669 & 400.000 & 149.7331 & 850 & 8234.07 & 8234.07 \\
\hline SA & $\mathbf{3 0 0 . 2 6 6 7}$ & $\mathbf{4 0 0 . 0 0 0}$ & $\mathbf{1 4 9 . 7 3 3 3}$ & $\mathbf{8 5 0}$ & $\mathbf{8 2 3 4 . 0 7}$ & $\mathbf{8 2 3 4 . 0 7}$ \\
\hline
\end{tabular}

Test Case 2: Thirteen Unit System $\left(P_{D}=2520 \mathrm{MW}\right)$

The system contains thirteen thermal generating units having non convex fuel cost characteristics. This system has more complexity and has multiple minima. For simulation purpose load demand on the system set at $2520 \mathrm{MW}$. The fuel cost coefficients are provided in (Sinha N. et al., 2003). The best cost obtained using the SA method is \$24169.91769418 per hour. Table 5 compares the numerical results with those of other approach. Results shows that the SA algorithm is capable of finding better cost than genetic algorithm (GA), Hybrid genetic/simulated-annealing approach (GA-SA), Hybridization of EP with sequential quadratic programming(EP_SQP), Hybrid particle swarm optimization sequential quadratic programming (PSO_SQP) (Aruldoss et al. 2004), improved coordination aggregated based PSO (ICA-PSO) (Vlachogiannis et. al. 2009), and modified group search optimizer algorithm (MGSO) ( Zare et al. 2012) and well comparable with differential evolution (DE) (Noman N et al. 2008). The convergence behavior is shown in Figure 2.

Test Case 3: 40 unit system

The test case consists of 40 generators with valve point loading and has a total load demand of 10,500 MW. The input data are given in [Sinha $\mathrm{N}$ et. al. (2003)]. This test case has larger and more complex than previous test cases. It has several local minima, and hence global minimum is very difficult to locate. The dispatched power generation results achieved using the proposed SA approach and other recently reported heuristic optimization approaches are given in Table 7. The optimum fuel cost achieved by the proposed SA algorithm is $\$ 121412.55369757$, which is better than the value reported by all other heuristic methods. The comparison of minimum cost, average cost and maximum cost by the proposed approach with the other recently reported results obtained using firefly algorithm (FA), modified group search optimizer (MGSO), hybrid swarm intelligence based harmony search algorithm (HHS), biogeography-based optimization (BBO), improved coordinated aggregation-based PSO (ICAPSO) ,bacterial foraging with nelder-mead (ABF_NM) local search, self-organizing hierarchical PSO (SOH_PSO), artificial bee colony(ABC) and other methods is depicted in Table 6. The minimum cost obtained by SA algorithm is better than all reported methods and the convergence characteristic is presented in Figure 3. 
Table 5: Results for 13 unit system for a demand of $2520 \mathrm{MW}$

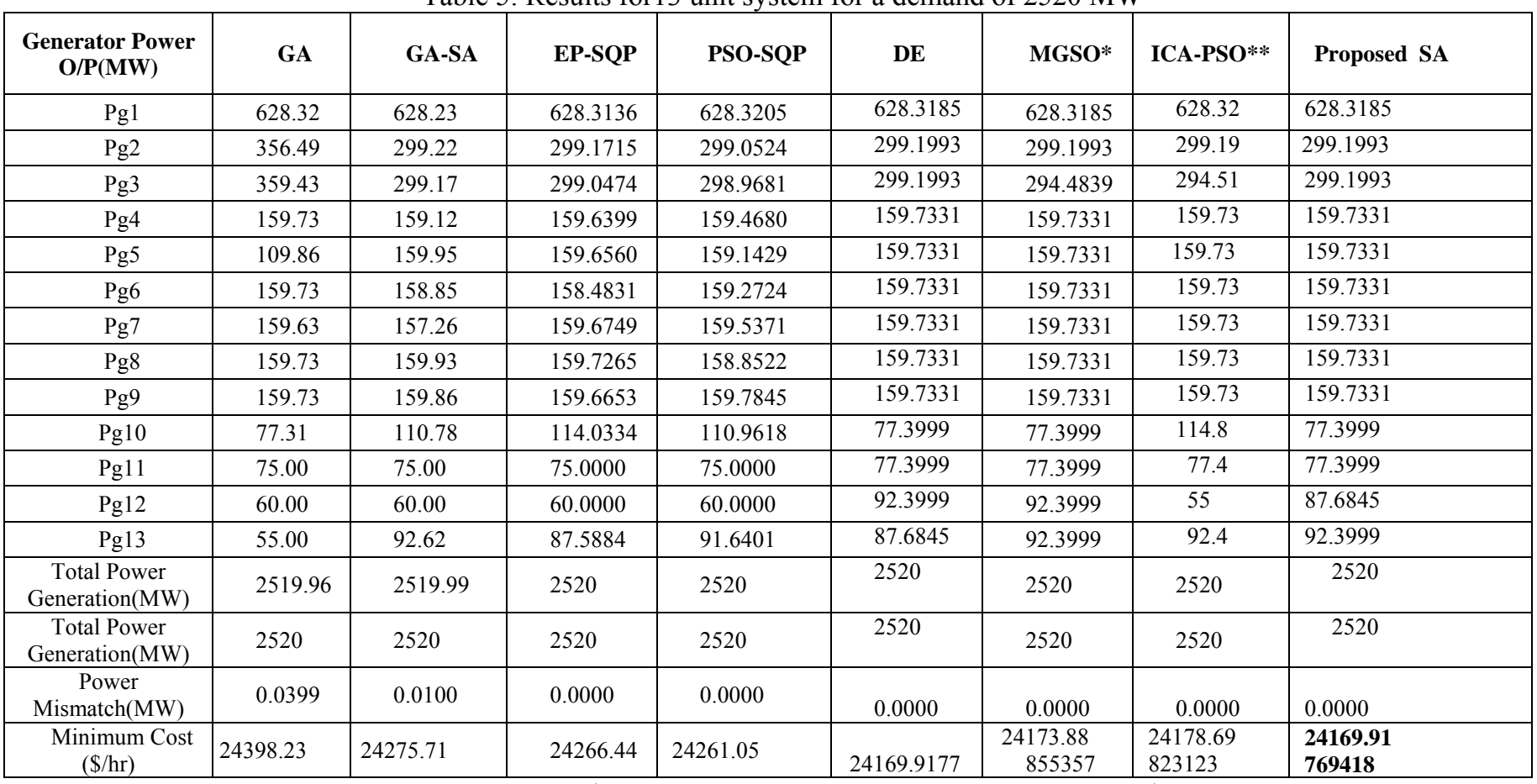

*Reported generation Cost: \$/hr 24,164.0508;** Reported generation Cost: \$/hr24168.91

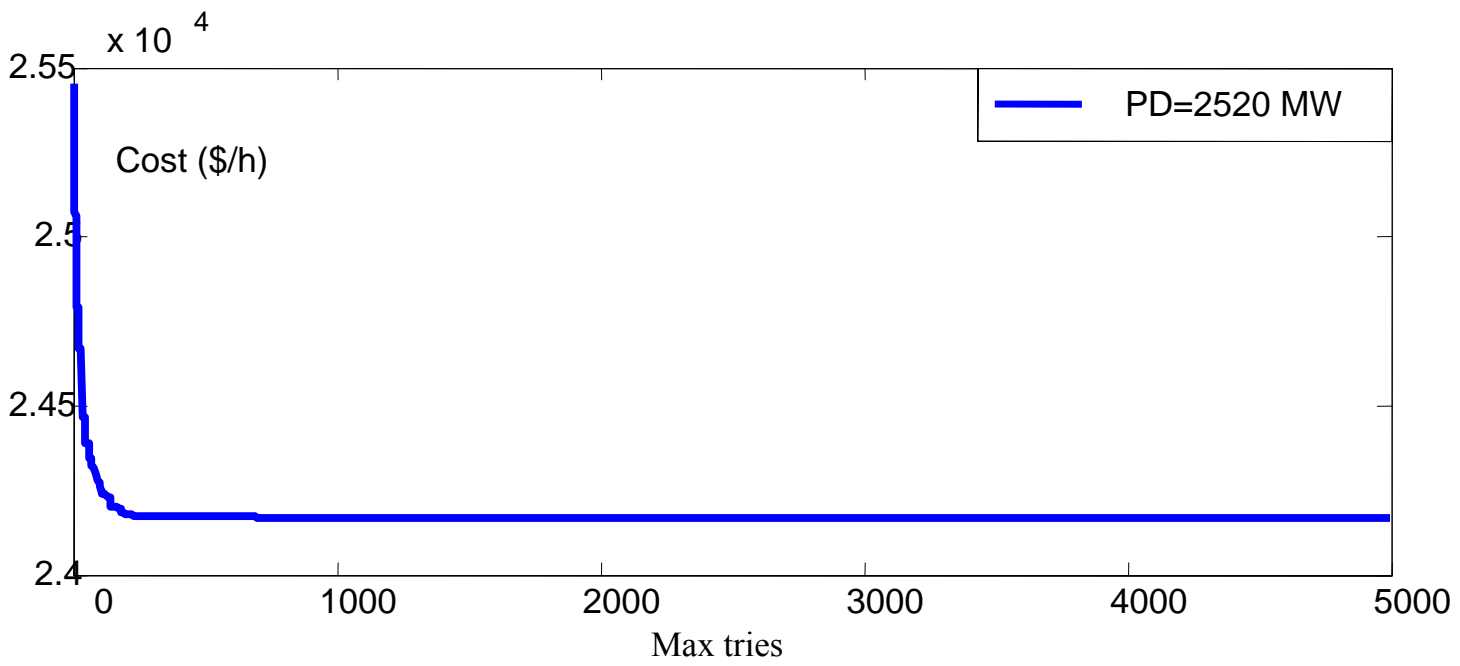

Figure 2: Convergence of 13 Generators system with $\mathrm{PD}=2520 \mathrm{MW}$

Table 6: Comparison of Results for 40 unit system

\begin{tabular}{|c|c|c|c|}
\hline \multirow{2}{*}{ Solution technique } & \multicolumn{3}{|c|}{ Production cost $(\$ / \mathrm{hr})$} \\
\hline & Min cost & Avg cost & Max cost \\
\hline IFEP (Sinha et al. 2003) & 122624.3500 & 123382.0000 & 125740.6300 \\
\hline NPSO LRS (Selvakumar et al . 2007) & 121664.4308 & 122209.3185 & 122981.5913 \\
\hline $\mathrm{ABC}($ Hemamalini et al .2008) & 121432.3900 & 121995.82 & 122123.77 \\
\hline SOH PSO (Chaturvedi et al. 2008) & 121501.1400 & 121853.57 & 122426.3000 \\
\hline ABF NM (Panigrahi et al. 2008) & 121423.6379 & 121814.9465 & ------- \\
\hline DE (Noman N et al. 2008) & 121416.29 & 121422.72 & 121431.47 \\
\hline ICA PSO (Vlachogiannis et. al. 2009) & 121413.20 & 121428.14 & 121453.56 \\
\hline BBO (Bhattacharya et al. 2010) & 121426.9530 & 121508.0325 & 121688.6634 \\
\hline HHS (Pandi et al . 2011) & 121415.5922 & 121615.8544 & ------- \\
\hline FA (Yang et al. 2012) & 121415.0522 & 121416.57 & 121424.56 \\
\hline MGSO ( Zare et al. 2012) & $121,412.5693$ & ------- & ------- \\
\hline SA & 121412.55369757 & 121418.05 & 121425.27579 \\
\hline
\end{tabular}


Table 7: Comparison of Results for 40 unit system (MD=10500 MW)

\begin{tabular}{|c|c|c|c|c|c|c|c|}
\hline $\begin{array}{l}\text { Power O/P } \\
\text { (MW) }\end{array}$ & SA & MGSO & FA & HHS & BBO & SOH_PSO & NPSO_LRS \\
\hline $\mathrm{P}_{1}$ & 110.8003 & 110.7999 & 110.8099 & 110.9030 & 110.8158 & 110.80 & 113.9761 \\
\hline$P_{2}$ & 110.7998 & 110.8003 & 110.8059 & 110.8642 & 111.0896 & 110.80 & 113.9986 \\
\hline $\mathrm{P}_{3}$ & 97.3999 & 97.4003 & 97.40230 & 97.4039 & 97.40261 & 97.40 & 97.4241 \\
\hline $\mathrm{P}_{4}$ & 179.7331 & 179.7336 & 179.7332 & 179.7339 & 179.7549 & 179.73 & 179.7327 \\
\hline $\mathrm{P}_{5}$ & 87.7999 & 87.7999 & 92.7070 & 91.4353 & 88.20832 & 87.80 & 89.6511 \\
\hline $\mathrm{P}_{6}$ & 140 & 140 & 140.0000 & 139.9999 & 139.9886 & 140.00 & 105.4044 \\
\hline $\mathrm{P}_{7}$ & 259.5994 & 259.5996 & 259.6004 & 259.6181 & 259.5935 & 259.60 & 259.7502 \\
\hline $\mathrm{P}_{8}$ & 284.5997 & 284.5997 & 284.6004 & 284.6035 & 284.6174 & 284.60 & 288.4534 \\
\hline $\mathrm{P}_{9}$ & 284.5997 & 284.6 & 284.6004 & 284.6164 & 284.6479 & 284.60 & 284.6460 \\
\hline $\mathrm{P}_{10}$ & 130 & 130 & 130.0028 & 130.0000 & 130.0298 & 130.00 & 204.8120 \\
\hline $\mathrm{P}_{11}$ & 94 & 94 & 168.8008 & 168.8046 & 94.01459 & 94.00 & 168.8311 \\
\hline $\mathrm{P}_{12}$ & 94 & 94 & 168.8008 & 168.7989 & 94.26367 & 94.00 & 94.0000 \\
\hline $\mathrm{P}_{13}$ & 214.76 & 214.7595 & 214.7606 & 214.7624 & 304.5153 & 304.52 & 214.7663 \\
\hline $\mathrm{P}_{14}$ & 394.2794 & 394.2794 & 304.5204 & 394.2790 & 394.264 & 304.52 & 394.2852 \\
\hline $\mathrm{P}_{15}$ & 394.2794 & 394.2794 & 394.2801 & 304.5197 & 304.5057 & 394.28 & 304.5187 \\
\hline $\mathrm{P}_{16}$ & 394.2794 & 394.2794 & 394.2801 & 394.2787 & 394.2472 & 394.28 & 394.2811 \\
\hline $\mathrm{P}_{17}$ & 489.2794 & 489.2794 & 489.2801 & 489.2876 & 489.3273 & 489.28 & 489.2807 \\
\hline $\mathrm{P}_{18}$ & 489.2794 & 489.2794 & 489.2801 & 489.2806 & 489.3047 & 489.28 & 489.2832 \\
\hline $\mathrm{P}_{19}$ & 511.2794 & 511.2794 & 511.2817 & 511.2844 & 511.3087 & 511.28 & 511.2845 \\
\hline $\mathrm{P}_{20}$ & 511.2794 & 511.2794 & 511.2817 & 511.2829 & 511.2495 & 511.27 & 511.3049 \\
\hline $\mathrm{P}_{21}$ & 523.2794 & 523.2794 & 523.2793 & 523.2794 & 523.3217 & 523.28 & 523.2916 \\
\hline $\mathrm{P}_{22}$ & 523.2794 & 523.2794 & 523.2793 & 523.2783 & 523.3144 & 523.28 & 523.2853 \\
\hline $\mathrm{P}_{23}$ & 523.2794 & 523.2794 & 523.2832 & 523.2812 & 523.3629 & 523.28 & 523.2797 \\
\hline $\mathrm{P}_{24}$ & 523.2794 & 523.2794 & 523.2832 & 523.2810 & 523.2883 & 523.28 & 523.2994 \\
\hline $\mathrm{P}_{25}$ & 523.2794 & 523.2794 & 523.2793 & 523.2815 & 523.2989 & 523.28 & 523.2865 \\
\hline $\mathrm{P}_{26}$ & 523.2794 & 523.2794 & 523.2793 & 523.2828 & 523.2802 & 523.28 & 523.2936 \\
\hline $\mathrm{P}_{27}$ & 10 & 10 & 10 & 10.0003 & 10.02817 & 10.00 & 10.0000 \\
\hline $\mathrm{P}_{28}$ & 10 & 10 & 10 & 10.0000 & 10.00321 & 10.00 & 10.0001 \\
\hline$P_{29}$ & 10 & 10 & 10 & 10.0000 & 10.0288 & 10.00 & 10.0000 \\
\hline $\mathrm{P}_{30}$ & 87.7999 & 87.7999 & 87.8008 & 88.7063 & 88.14595 & 97.00 & 89.0139 \\
\hline $\mathrm{P}_{31}$ & 190 & 190 & 189.9989 & 189.9999 & 189.9913 & 190.00 & 190.0000 \\
\hline $\mathrm{P}_{32}$ & 190 & 190 & 189.9989 & 190.0000 & 189.9888 & 190.00 & 190.0000 \\
\hline$P_{33}$ & 190 & 190 & 189.9989 & 190.0000 & 189.9998 & 190.00 & 190.0000 \\
\hline $\mathrm{P}_{34}$ & 164.7998 & 164.8025 & 164.8036 & 164.8519 & 164.8452 & 185.20 & 199.9998 \\
\hline $\mathrm{P}_{35}$ & 200 & 194.3935 & 164.8036 & 164.8967 & 192.9876 & 164.80 & 165.1397 \\
\hline $\mathrm{P}_{36}$ & 194.3973 & 200 & 164.8036 & 164.8205 & 199.9876 & 200.00 & 172.0275 \\
\hline$P_{37}$ & 110 & 110 & 110 & 110.0000 & 109.9941 & 110.00 & 110.0000 \\
\hline $\mathrm{P}_{38}$ & 110 & 110 & 110 & 109.9997 & 109.9992 & 110.00 & 110.0000 \\
\hline $\mathrm{P}_{39}$ & 110 & 110 & 110 & 110.0000 & 109.9833 & 110.00 & 93.0962 \\
\hline $\mathrm{P}_{40}$ & 511.2794 & 511.2794 & 511.2794 & 511.2836 & 511.2794 & 511.28 & 511.2996 \\
\hline $\begin{array}{ll}\text { Total Cost } \\
(\$ / \mathrm{h})\end{array}$ & 121412.5536975 & $121,412.5693$ & 121415.0522 & 121415.5922 & 121426.593 & 121501.14 & 121664.4308 \\
\hline
\end{tabular}




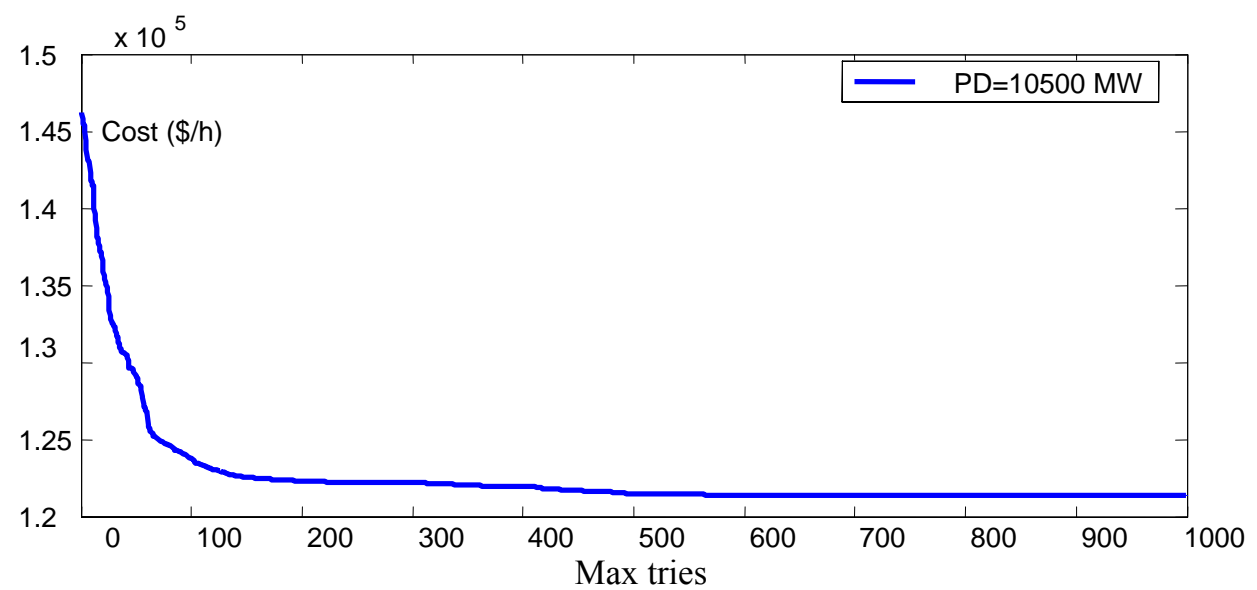

Figure 3: Convergence of 40 generators system with $\mathrm{PD}=10500 \mathrm{MW}$

Test Case4: Eighteen Unit System $\left(P_{D}=433.22 \mathrm{MW}\right)$

The fourth test case considers the Greek island of Crete consisting of 18 thermal units system. The technical limits and the quadratic cost coefficients for the above system is adopted from (Ioannis et al. 2003). The maximum power output of the generators set is $433.22 \mathrm{MW}$. Various tests were made with a varying percentage of the maximum power as demand. Table 8 summarizes the test results in terms of optimum power generation dispatch, and it is evidently seen from Table 9 that the proposed technique provided better results compared to other reported evolutionary algorithm techniques. Hence it is clear that the SA performs very well for finding the optimum solution of the ELD problems, while it takes relatively low computational time per iteration. Figure 4 shows the convergence behavior of test case 4 with a varying percentage of the maximum power as demand.

Table 8: Comparison of Results for 18 unit system (MD=433.22 MW)

\begin{tabular}{|c|c|c|c|c|}
\hline $\begin{array}{l}\text { Unit power } \\
\text { output(MW) }\end{array}$ & $0.70 * \mathrm{MD}$ & $0.80 * \mathrm{MD}$ & $0.90 * \mathrm{MD}$ & $0.95 * \mathrm{MD}$ \\
\hline Pg1 & 15.0000 & 15.0000 & 15.0000 & 15.0000 \\
\hline Pg2 & 45.0000 & 45.0000 & 45.0000 & 45.0000 \\
\hline Pg3 & 25.0000 & 25.0000 & 25.0000 & 25.0000 \\
\hline $\mathrm{Pg} 4$ & 25.0000 & 25.0000 & 25.0000 & 25.0000 \\
\hline Pg5 & 25.0000 & 25.0000 & 25.0000 & 25.0000 \\
\hline Pg6 & 3.0000 & 3.0485 & 8.2379 & 13.7063 \\
\hline Pg7 & 3.0000 & 3.1334 & 8.2379 & 13.7063 \\
\hline Pg8 & 12.2800 & 12.2800 & 12.2800 & 12.2800 \\
\hline Pg9 & 12.2800 & 12.2800 & 12.2800 & 12.2800 \\
\hline Pg10 & 12.2800 & 12.2800 & 12.2800 & 12.2800 \\
\hline Pg11 & 12.2800 & 12.2800 & 12.2800 & 12.2800 \\
\hline $\operatorname{Pg} 12$ & 14.8322 & 20.9144 & 24.0000 & 24.0000 \\
\hline $\operatorname{Pg} 13$ & 3.0000 & 3.0000 & 3.1636 & 6.4132 \\
\hline Pg14 & 21.0494 & 30.2892 & 36.2000 & 36.2000 \\
\hline $\operatorname{Pg} 15$ & 23.1610 & 32.5145 & 42.5270 & 45.0000 \\
\hline $\operatorname{Pg} 16$ & 24.0457 & 32.7503 & 37.0000 & 37.0000 \\
\hline Pg17 & 24.0457 & 33.8056 & 43.4116 & 45.0000 \\
\hline $\operatorname{Pg} 18$ & 3.0000 & 3.0001 & 3.0000 & 6.4132 \\
\hline $\begin{array}{l}\text { Total power output } \\
\text { (MW) }\end{array}$ & 303.254 & 346.576 & 389.898 & 411.559 \\
\hline Minimum Cost (\$/hr) & 20386.30950 & 23855.85595 & 27653.78063 & 29731.06662 \\
\hline Average cost(\$/h) & 20389.0000 & 23856.4600 & 27655.5700 & 29731.6500 \\
\hline $\begin{array}{c}\text { Standard } \\
\text { deviation }(\$ / \mathrm{hr})\end{array}$ & 2.39 & 0.88 & 2.94 & 0.85 \\
\hline $\begin{array}{c}\text { CPU } \\
\text { time/iteration(sec) }\end{array}$ & 0.037 & 0.030 & 0.042 & 0.043 \\
\hline
\end{tabular}




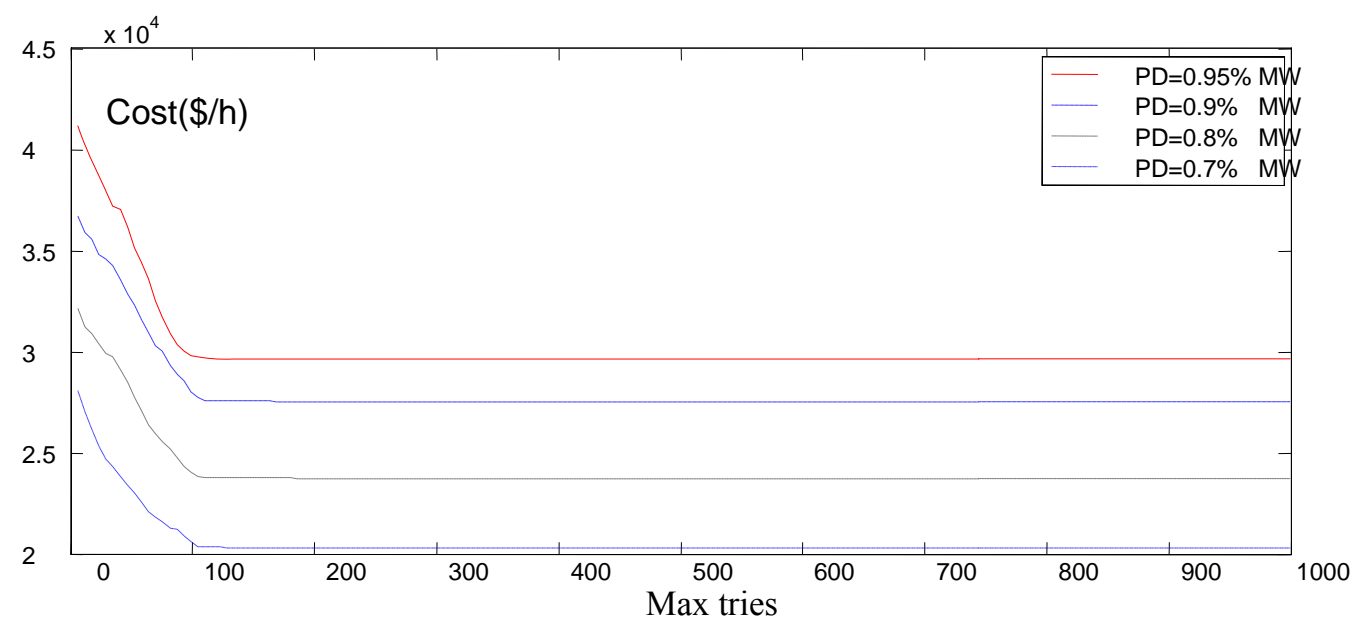

Figure 4: Convergence Characteristics of Eighteen Unit System with various loads

Table 9: Comparison of Results for 18 unit system

\begin{tabular}{|c|c|c|c|c|}
\hline Solution technique & $\mathbf{0 . 9 5} * \mathbf{M D}$ & $\mathbf{0 . 9 0} * \mathbf{M D}$ & $\mathbf{0 . 8 0} * \mathbf{M D}$ & $\mathbf{0 . 7 0} * \mathbf{M D}$ \\
\hline $\begin{array}{c}\lambda \text {-iteration } \\
\text { (Ioannis G. } \text { et al.,2003) }\end{array}$ & 29731.05 & 27652.47 & 23861.58 & 20393.43 \\
\hline $\begin{array}{c}\text { Binary GA } \\
\text { (Ioannis G. } \text { et al.,2003) }\end{array}$ & 29733.42 & 27681.05 & 23980.24 & 20444.68 \\
\hline $\begin{array}{c}\text { Real-coded GA } \\
\text { (Ioannis G. } \text { et al.,2003) }\end{array}$ & 29731.05 & 27655.53 & 23861.58 & 20396.39 \\
\hline $\begin{array}{c}\text { ABC } \\
\text { (Dixit G. } \text { et al.,2011) }\end{array}$ & 29730.80 & 27653.30 & 23859.40 & 20391.60 \\
\hline SA & $\mathbf{2 9 7 3 1 . 0 6 6 6 2 0}$ & $\mathbf{2 7 6 5 3 . 7 8 0 6 3 0}$ & $\mathbf{2 3 8 5 5 . 8 5 5 9 5 0}$ & $\mathbf{2 0 3 8 6 . 3 0 9 5 0 3}$ \\
\hline
\end{tabular}

Table 9 shows that the minimum fuel cost obtained by the SA algorithm in case of varying percentage of the maximum power demand is better than all other reported results.So it can be concluded that the SA method is computationally more efficient as compared to previously reported methods.

\section{Conclusion}

This paper has proposed the SA algorithm for ELD problems, a stochastic optimization technique based on the process of annealing in thermodynamics is presented. In this work we have investigated the potential of the SA algorithm in solving particularly non-smooth cost functions. The ELD problem has become a very important issue with the depleting reserves of coal and the increase in fuel prices. An appropriate planning and scheduling of available generating units may save millions of dollars per year in production cost. First a study was carried out to determine the optimal values of tuning parameters of the SA and then the best set of parameters were fixed for the rest of the studies. Selection of optimum combination of parameters for SA algorithm is an essential task, since the success of the algorithm depends on it. The feasibility of the proposed method for solving ELD problems is verified by using 3,13, 40 and 18 generator test systems, out of which the first three test cases are with valve-point loading effects. The outcome of the analysis supports the claim that the proposed method was found to provide better solutions than solutions of other methods reported so far. Test case four considers the Greek island of Crete consisting of 18 thermal units system, in which the robustness of the SA method was verified by the change in load demands of the problem. The obtained SA results for this problem were not the best, but very close to previously mentioned methods. Considering all the results of ELD problems with different characteristics, dimensions, demands and constraints, it can be concluded that SA is powerful optimization technique for constrained optimization. The results obtained are either better or are matching in accuracy with previously proposed methods. Therefore, SA based optimization is a promising alternative approach for solving complicated problems in power system. The findings of this paper confirm that the proposed SA algorithm can be applied for solving other power system problems with different levels of complexity. 


\section{Nomenclature}

$\begin{array}{ll}F_{t}^{\text {cost }} & : \text { Total power production cost } \\ f_{i}\left(P_{i}\right) & : \text { Fuel cost corresponding to } \mathrm{i}^{\text {th }} \text { generator for output power } \mathrm{P}_{\mathrm{i}} \\ a_{i}, b_{i}, c_{i} & : \text { Cost coefficients of } \mathrm{i}^{\text {th }} \text { generator } \\ P_{i} & : \text { Real power output }(\mathrm{MW}) \text { of } \mathrm{i}^{\text {th }} \text { generator corresponding to time period } \mathrm{t} \\ e_{i}, f_{i} & : \text { Cost coefficients to effectively model the valve point loading effect } \\ B_{i j}, B_{i 0}, B_{00} & : \text { Loss coefficients } \\ P_{D} & : \text { Power demand } \\ P_{L} & : \text { Power loss } \\ P_{i}^{\max } & : \text { Upper bound for power outputs of the } \mathrm{i}^{\text {th }} \text { generating unit } \\ P_{i}^{\min } & : \text { Lower bound for power outputs of the } \mathrm{i}^{\text {th }} \text { generating unit }\end{array}$

\section{Acknowledgement}

The authors are thankful to Director, Madhav Institute of Technology \& Science, Gwalior (M.P) India for providing support and facilities to carry out this research work.

\section{References}

Aarts E., Korst Jan H.M., Laarhoven Peter and Van J. M., 1988. A Quantitative Analysis of the Simulated Annealing Algorithm. A Case Study for the Travelling Salesman Problem. Journal of Statistical Physics. Vol. 50, pp. 1-2.

AlRashidi M. R., and El-Hawary M. E. 2007, Hybrid particle swarm optimization approach for solving the discrete OPF problem considering the valve loading effects, IEEE Trans. Power Syst., vol. 22, no. 4, pp. 2030-2038.

Aruldoss T., Victoire A. and Jeyakumar A.E., 2004. Hybrid PSO-SQP for economic dispatch with valve-point effect. Elect. Power syst., Res., Vol. 71, No. 1, pp. 51-59.

Bhattacharya A. and Chattopadhyay P.K., 2010. Biogeography-Based optimization for different economic load dispatch problems. IEEE Trans. Power Syst., Vol. 25, No. 2, pp. 1064-1077.

Choudhary B.H. and Rahman S., 1990. A review of recent advances in economic dispatch. IEEE Trans Power Syst., Vol. 5, No. 4, pp. 1248-59.

Coelho Leandro dos Santos, and Mariani Viviana Cocco, 2006. Combining of Chaotic Differential Evolution and Quadratic Programming for Economic Dispatch Optimization With Valve-Point Effect, IEEE Transactions on Power Systems, Vol. 21, No. 2, pp. 989-995.

Chen C.H. and Yeh S.N., 2006. Particle Swarm Optimization for Economic Power Dispatch with Valve -Point Effects. IEEE Trans. pp 1-5.

Coelho L.S. and Mariani V.C., 2006. Combining of chaotic differential evolution and quadratic programming for economic dispatch optimization with valve-point effect. IEEE Trans. Power Syst., Vol. 21, No. 2, pp. 989-996.

Chaturvedi K T, Pandit M. and Srivastava L.,2008 Self-Organizing Hierarchical Particle Swarm Optimization for Non-Convex Economic Dispatch. IEEE Trans. Power Syst., Vol. 23, No. 3, pp. 1079-1087.

Coelho L.S., Souza RCT and Mariani VC., 2009. Improved differential evolution approach based on cultural algorithm and diversity measure applied to solve economic load dispatch problems. Math comput simulate. Vol. 79, no. 10, pp. 3136-47.

Chen Chung-Lung, 2007. Non-convex economic dispatch: A direct sarch approach. Energy Conservation and Managment. Vol.48, pp219-225.

Dixit G., Dubey H. M., Pandit M. and Panigrahi B.K., 2011. Economic Load Dispatch using Artificial Bee Colony Optimization. International Journal of Advanced in Electronics Engineering. pp. 129-124.

Dowsland K.A., 1995. Simulated Annealing in Modern Heuristic Techniques for Combinatorial Problem. McGraw-Hill.

Happ H.H., 1971. Optimal power dispatch - a comprehensive survey. IEEE Trans Power Apparatus Syst. PAS-96, pp. 841-54

Immanuel Selvakumar A, and Thanushkodi K., 2007. A new particle swarm optimization solution to non-convex economic dispatch problems. IEEE Trans Power Syst., Vol. 22, No. 1, pp. 42-51.

Hemamalini S. and Simon S. P. 2008, Economic Load Dispatch with valve point effect using Artificial Bee Colony Algorithm, XXXII National System Conference, NSC 2008, December17-19,pp.525-530.

Ioannis G., Damousis, Anastasios G. Bakirtzis and Petros S. Dokopoulos, 2003. Network-Constrained Economic Dispatch Using Real-Coded Genetic Algorithm. IEEE Trans on power system, Vol. 18, No. 1,pp. 198-204.Jiejin C, Xiaoqian M, Lixiang L, and Haipeng P., 2007. Chaotic particle swarm optimization for economic dispatch considering the generator constraints. Energy Convers Manage, Vol. 48, pp. 645-53.

John G.V. lachogiannis and K.Y. Lee, 2009. Economic load dispatch - a comparative study on heuristic optimization techniques with an improved coordinated aggregation-based PSO. IEEE Trans. Power Syst., Vol. 24, No. 2, pp. 991-1001. 
Kolahan F., and Abachizadeh M., 2010. Optimizing Turning Parameters for cylindrical Parts using simulated Annealing Method. International journal of Engineering and Applied Science, Vol. 6, No. 3, pp.149-152.

Kirkpatrick S., Gellat C. and Vecchi M., 1983. Optimization by Simulated Annealing. Science, Vol. 220, pp. 45-54.

Lee K.Y. et al.,1984. Fuel cost minimization for both real and reactive power dispatches. IEE Proc C, Gen Transm Distrib, Vol. 131, No. 3, pp. 85-93.

Liu D. and Cai Y., 2005. Taguchi method for solving the economic dispatch problem with non-smooth cost functions. IEEE Trans. Power Syst., Vol. 20, No. 4, pp. 2006-2014.

Lundy M., 1985. Applications of the annealing algorithm to combinatorial problems in statics. Biometrika, Vol. 75, pp. 191-198.

Meng Ke, Wang H.G. and Dong Z.Y., 2010. Quantum-inspired particle swarm optimization for valve-point economic load dispatch. IEEE Trans. Power Syst., Vol. 25, No.1, pp. 215-222.

Meng K., 2007. Research of fuzzy self-adaptive immune algorithm and its application. M. E thesis, east China Univ. Sci. Technol., Shanghai, China.

Metropolis N. , Rosenbluth .A, Rosenbluth M., Teller M., and Teller E. (1953) Equation of State Calculations by Fast Computing Machines. J. Chem. Phys., vol. 21 (6), p. 1087-92.

Ning Z.G., Meng K, Yan X.F., and Qian F., 2007. An improved particle swarm algorithm and its application in soft sensor modeling. J. East China Univ.Sci.Technol., Vol. 33, No. 3, pp. 400-404.

Noman N and Iba H., 2008. Differential evolution for economic load dispatch problems. Electr Power Syst Res, Vol. 78, No. 3, pp.1322-31.

Padmanabhan B., Sivakumar R. S., Jasper J., and Victoire T. Aruldoss Albert. 2011. Bacterial Foraging Approach to Economic Load Dispatch Problem with Non Convex Cost Function, Swarm, Evolutionary, and Memetic Computing (Lecture Notes in Computer Science), Volume 7076, pp 577-584.

Pandi V. R., Panigrahi B. K., Bansal R.C., Das S. and Mohapatra A. 2011, Economic Load Dispatch Using Hybrid Swarm Intelligence Based Harmony Search Algorithm, Electric Power Components and Systems, Vol. 39.pp.751-767.

Panigrahi C. K., Chattopadhyay P. K. , Chakrabarti R. N. and Basu M. 2006, Simulated annealing technique for dynamic economic dispatch, Electric Power Components and Systems, Vol. 34, pp. 577-586.

Panigrahi B. K. and Pandi V R.2008 Bacterial foraging optimization nelder mead hybrid algorithm for economic load dispatch. IET Gener. Transm. Distrib. Vol. 2, No. 4, pp 556-565.

Park J.H., Kim Y.S., Eom I.K., and Lee K. Y., 1993. Economic Load Dispatch for price wise Quadratic Cost Function Using Hopfield Neural Network. IEEE Trans. on Power Systems, Vol. 8, No. 3, pp. 1030-1038.

Park J.B., Lee K.S., Shin J. R. and Lee K.Y., 2005. A particle swarm optimization for economic dispatch with non-smooth cost functions. IEEE Trans. Power Syst., Vol. 20, No. 1, pp. 34-42.

Pandian S. Muthu Vijaya and Thanushkodi K., 2011. An Evolutionary Programming Based Efficient Particle Swarm Optimization for Economic Dispatch Problem with Valve-Point Loading. European Journal of Scientific Research, Vol. 52 No.3, pp.385-397.

Pereira-Neto A., Unsihuay C. and Saavedra O.R, 2005, Efficient evolutionary strategy optimisation procedure to solve the nonconvex economic dispatch problem with generator constraints, IEE Proc. Gen. Transm. Distrib. 152(5) pp.653-660.

Sinha N., chakrabarti R. and chattopadhyay P. K., 2003. Evolutionary programming techniques for economic load dispatch. IEEE Trans. Evol. Comput., Vol. 7, No. 1, pp. 83-94.

Song Y.-H., Johns A., Aggarwal R., 1996. Computational Intelligence Applications to Power Systems, Kluwer Academic Publishers, Norwell USA.

SunD.I., AshleyB., BrewerB., Hughes A., and Tinney W.F. 1984, "Optimal power flow by Newton approach," IEEE Power Apparatus and Systems, vol. PAS-103, no. 10, pp. 2864 - 2880.

Sydulu M.A., 1999. Very fast and effective non-iterative "Lamda Logic Based" algorithm for economic dispatch of thermal units. In: Proceedings of IEEE region 10 conference TENCON, Vol. 2, pp. 1434-7

Vanaja B., Hemamalini S. and Simon Sishaj p., 2008. Genetic algorithm based economic load dispatch with valve point effect, $10^{\text {th }}$ IASTED International Conference on Power and Energy Systems, April 16-18, PES- 2008.

Vishwakarma K.K, Dubey H.M. 2012, Simulated Annealing Based Optimization for Solving Large Scale Economic Load Dispatch Problems, International Journal of Engineering Research \& Technology (IJERT), Vol. 1 ,No.3, pp.----

Walter D.C. and Sheble G.B., 1993. Genetic algorithm solution of economic dispatch with valve-point loading, IEEE Trans. Power Syst., Vol. 8, No. 3, pp. 1125-1132.

Wong, K.P., Fung C.C., 1993, Simulated annealing based economic dispatch algorithm, Generation, Transmission and Distribution, IEE Proceedings C, vol. 140, no. 6, pp. $4509-515$.

Wong, K.P., 1994., Genetic and genetic/simulated-annealing approaches to economic dispatch, Generation, Transmission and Distribution, IEE Proceedings, vol. 141, no. 5, pp. $507-513$.

Wood A.J. and Wollenberg B. F., 1996. Power Generation Operation and Control. Wiley, New York, $2^{\text {nd }}$ ed.

Yang H.T. and Yang P.C. and Huang C.L., 1996. Evolutionary Programming based economic dispatch for units with non-smooth fuel cost functions. IEEE Trans. Power Syst., Vol. 11, no. 1, pp. 112-118. 
Yang Xin-She, Hosseini Seyyed Soheil Sadat and Gandomi Amir Hossein. 2012. Firefly Algorithm for solving non-convex economic dispatch problems with valve loading effect. Journal of Applied Soft Computing, Volume 12 Issue 3, Pages 11801186.

Yao X., Liu Y. and Lin G., 1999. Evolutionary programming made faster. IEEE Trans. Evol. Comput., Vol. .3, No.2, pp. 82-102. Yuryevich J, and Wong K.P. 1999, “Evolutionary programming based optimal power flow algorithm," IEEE Trans. Power Syst., vol. 14, no. 4, pp. 1245-1250.

Zare k., Haque M.T., and Davoodi E.,2012, Solving non-convex economic dispatch problem with valve point effects using modified group search optimizer method. Electric Power Systems Research, Vol. 84, pp. 83- 89.

\section{Biographical notes}

Kamlesh Kumar Vishwakarma obtained his B.E. degree in Electrical Engineering from I.G.E.C., Sagar, (India) in 2010. He is presently doing M.E. in Industrial Systems and Drives (ISD) from M.I.T.S., Gwalior, (India).

Hari Mohan Dubey obtained his M.E. degree in Electrical Engineering from Madhav Institute of Technology \& Science Gwalior (India) in 2002. He is currently working as Assistant Professor in Department of Electrical Engineering, M.I.T.S., Gwalior, (India). His areas of research are Computational intelligence algorithm and their applications to power system.

Manjaree Pandit obtained her M.Tech degree in Electrical Engineering from Maulana Azad College of Technology, Bhopal, (India) in 1989 and Ph.D. degree from Jiwaji University Gwalior (India) in 2001. She is currently working as Professor in Department of Electrical Engineering, M.I.T.S., Gwalior, (India). Her areas of interest are Power System Security Analysis, Optimization using soft computing/ evolutionary methods, ANN and Fuzzy neural applications to Power System.

Bijaya Ketan Panigrahi obtained his M. Tech degree in Electrical Engineering from University College of engineering, Burla, sambalpur, Orissa in 1995 and $\mathrm{Ph.D}$. degree from sambalpur University Orissa (India) in 2004. He is currently working as Associate Professor in Department of Electrical Engineering, IIT, Delhi, (India). His areas of research includes the study of advanced signal processing techniques, Computational intelligence algorithm and their applications to electrical engineering, in particular to domain of power system. He is also works in area of application of evolutionary computing techniques to solve problem related to power system planning, operation and control.

Received April 2012

Accepted November 2012

Final acceptance in revised form December 2012 